\title{
Giant Prolactinomas: Case Series and Review of the Literature
}

\author{
Vishnu Vardhan Garla ${ }^{\mathrm{a}, \mathrm{d}}$, Shiva Gosi ${ }^{\mathrm{b}}$, Sravanthi Palakodety ${ }^{\mathrm{b}}$, Swetha Kanduria \\ Karthik Kovvuru ${ }^{\mathrm{a}}$, Manasa Gunturu ${ }^{\mathrm{c}}$, Lillian Lien ${ }^{\mathrm{a}}$
}

\begin{abstract}
Giant prolactinomas are rare and constitute only $2-3 \%$ of prolactinomas. They are defined as prolactinomas greater than $4 \mathrm{~cm}$ in size with a prolactin level of $>1,000 \mu \mathrm{g} / \mathrm{L}$. Unlike prolactinomas, giant prolactinomas have a male preponderance and present a decade earlier in men as compared to women. Giant prolactinomas may present with galactorrhea, irregular periods or decreased libido. Due to their large size, they can involve surrounding brain structures and may present with hydrocephalus, dizziness, seizures, deafness, and cognitive dysfunction. Laboratory assessment may reveal a falsely low prolactin level secondary to "hook effect" which is due to saturation of the capture and detection antibodies used in the assay. Dilution of the sample would show a paradoxical increase in prolactin levels confirming the hook effect. Magnetic resonance imaging (MRI) is warranted to assess the extent of the tumor. Dopamine agonists are the treatment of choice in giant prolactinomas and lead to rapid resolution of symptoms, normalization of prolactin levels, and reduction in the size of the tumors. Refractory giant prolactinomas may be treated with surgery, temozolomide or radiotherapy. Giant prolactinomas can pose unique diagnostic and management challenges because of atypical presentations and confounding laboratory assessments. We present four cases of giant prolactinomas each presenting in a unique manner and discuss the diagnostic and management dilemmas associated with them.
\end{abstract}

Keywords: Prolactinoma; Giant prolactinoma; Pituitary tumor

\section{Introduction}

Giant prolactinomas are rare endocrine tumors and constitute

Manuscript submitted November 6, 2020, accepted November 16, 2020

Published online December 22, 2020

aDepartment of Internal Medicine, University of Mississippi Medical Center, Jackson, MS, USA

${ }^{b}$ Department of Hospital Medicine, Banner Thunderbird Medical Center, Phoenix, AZ, USA

'Department of Neurology, University of Mississippi Medical Center, Jackson, MS, USA

${ }^{\mathrm{d} C o r r e s p o n d i n g ~ A u t h o r: ~ V i s h n u ~ V a r d h a n ~ G a r l a, ~ D e p a r t m e n t ~ o f ~ I n t e r n a l ~ M e d i-~}$ cine, University of Mississippi Medical Center, Jackson, MS, USA.

Email:vgarla@umc.edu

doi: https://doi.org/10.14740/jem652 only about $2-3 \%$ of prolactin-secreting tumors. They are more common in men (nine-fold) and occur about 10 years earlier in men as compared to women [1].They can present unique challenges in diagnosis and management as they can present with a variety of atypical symptoms, unclear laboratory assessments as well as resistance to conventional treatments.

We present four cases of giant prolactinomas with diverse clinical presentations and also review the relevant literature.

\section{Case Reports}

\section{Case 1}

A 22-year-old male patient was seen in the emergency room after a motor vehicle accident. Over the past year, he had multiple episodes of epistaxis and had profound fatigue. There was no other significant past medical history. Computed tomography (CT) scan showed a large suprasellar mass. Magnetic resonance imaging (MRI) revealed a $12 \mathrm{~cm}$ mass likely arising from the sella, involving bilateral cavernous sinus with mass effects on bilateral temporal lobes causing a midline shift of around $6 \mathrm{~mm}$. The pituitary hormonal assessment was significant for a very high prolactin of $>4,700$ $\mathrm{ng} / \mathrm{mL}(0-25 \mathrm{ng} / \mathrm{mL}$ ) (Table 1) consistent with the diagnosis of prolactinoma. Bromocriptine was started however the patient's adherence to the treatment regimen was inconsistent. Six months later the patient presented with clear fluid discharge from the nose and severe headaches due to a cerebrospinal fluid (CSF) leak. MRI showed an improvement in the size of the tumor (Fig. 1). CSF analysis revealed a white blood cell count (WBC) of 1,555 cells $/ \mathrm{mm}^{3}$ consistent with the diagnosis of meningitis. The patient was started on antibiotics and the CSF leak repaired. Upon follow-up over the next 8 years MRIs showed continued reduction in the size of the tumor to $2.5 \mathrm{~cm}$ (Fig. 1). Prolactin levels decreased but never completely normalized secondary to the patient's noncompliance.

\section{Case 2}

A 39-year-old male patient presented to the emergency room with seizures. He had a 2-year history of macroprolactinoma and was non-compliant with cabergoline. Seizures had started 
Table 1. Pituitary Hormonal Assessment at the Time of Diagnosis

\begin{tabular}{|c|c|c|c|c|}
\hline & Case 1 & Case 2 & Case 3 & Case 4 \\
\hline Prolactin $(0-25 \mathrm{ng} / \mathrm{mL})$ & $>4,700$ & 4,568 & $>4,700$ & 1.4 \\
\hline IGF-1 (116 - $341 \mathrm{ng} / \mathrm{mL})$ & 256 & 257 & 119 & 122 \\
\hline Free $\mathrm{T} 4(0.9-1.7 \mathrm{ng} / \mathrm{dL})$ & 1.64 & 0.82 & 0.54 & 1.2 \\
\hline ACTH $(7.2-63.3 \mathrm{pg} / \mathrm{mL})$ & 55 & 43 & 19 & 5.7 \\
\hline Follicle stimulating hormone $(0.95-11.95 \mathrm{mIU} / \mathrm{mL})$ & 3 & 1.1 & 5.02 & 6.14 \\
\hline
\end{tabular}

IGF-1: insulin like growth factor-1; T4: thyroxine; ACTH: adrenocorticotropic hormone.

4 months ago and were characterized by an aura (sensation of warmth), olfactory hallucinations and oral automatisms. Post-seizure, the patient experienced extreme fatigue. On examination, the patient had loss of lateral visual fields on confrontation testing. The pituitary hormonal panel revealed an extremely high prolactin level of 4,568 ng/mL $(0-25 \mathrm{ng} / \mathrm{mL})$ (Table 1). MRI showed a $4.5 \mathrm{~cm}$ sellar mass with mass effect on the optic chiasma, extending laterally into the left temporal lobe (Fig. 2). Electroencephalogram (EEG) showed spikes in the left temporal area consistent with temporal lobe epilepsy. Three months after initiation of treatment with cabergoline there was significant improvement with prolactin decreasing from $4,500 \mathrm{ng} / \mathrm{mL}$ to $7 \mathrm{ng} / \mathrm{mL}$. The size of the tumor also reduced by $30 \%$ in 3 months. MRI done 6 years after the initial diagnosis still showed a residual mass of $2.5 \mathrm{~cm}$, perhaps most likely due to the continued non-compliance with cabergoline (Fig 2).

\section{Case 3}

A 17-year-old female patient presented with a history of primary amenorrhea. She did not report any headaches, galactorrhea or visual issues. No other significant past medical and surgical history. She had previously presented to her pediatrician and was diagnosed with constitutional delay of puberty. Upon examination, there was no development of any secondary sexual characteristics. The patient was short in stature with a height of $147.3 \mathrm{~cm}$. Her expected mid-parental height was $162.6 \mathrm{~cm}$. Karyotype revealed a normal female XX chromosomes ruling out Turner's syndrome. Ultrasonography (USG) of the abdomen showed normal prepubertal adnexal structures. Laboratory assessment revealed normal pituitary hormonal panel except for a very high prolactin of $>4,700$ $\mathrm{ng} / \mathrm{mL}(0-25 \mathrm{ng} / \mathrm{mL})$ (Table 1$)$. MRI of the pituitary gland showed a $4 \mathrm{~cm}$ sellar mass compressing the optic chiasma and pre-chiasma optic nerves (Fig. 3). Visual field assessment showed bitemporal hemianopsia. She was started on cabergoline $1 \mathrm{mg}$ twice weekly and had a dramatic response with prolactin decreasing from $>4,700 \mathrm{ng} / \mathrm{mL}$ to $7.2 \mathrm{ng} / \mathrm{mL}$; however, the patient continued to have amenorrhea. Follow-up MRI in 9 months showed a $50 \%$ decrease in the size of the tumor (Fig. 3).

\section{Case 4}

A 55-year-old male patient presented with a history of progressive cognitive impairment for the last 4 years. Past medical history was significant for type 2 diabetes mellitus which was well controlled on metformin. Vitals revealed a blood pressure was $139 / 95 \mathrm{~mm} \mathrm{Hg}$, heart rate of $79 / \mathrm{min}$, and a temperature of $36.4{ }^{\circ} \mathrm{C}$. MRI showed a large heterogeneous $7 \times 6 \mathrm{~cm}$ mass arising from the sellar region compressing the lateral ventricles and involving the bilateral cavernous sinus. Pituitary hormonal assessment results done before surgery were normal except for a low prolactin of $1.4 \mathrm{ng} / \mathrm{mL}(0-25 \mathrm{ng} / \mathrm{mL})$ (Table 1). Serial dilution of the sample was performed which showed no increase in the prolactin levels eliminating hook effect. A right frontotemporal craniotomy was performed, and most of the tumor was excised excepting for the portion dorsal to the anterior communicating artery. Postoperatively patient was started on hydrocortisone for adrenal insufficiency. Pathology of the tumor showed positive staining for prolactin consistent with a prolactinoma (Fig. 4). The combination of a low prolactin but positive immunostaining on pathology is consistent with the diagnosis of a silent prolactinoma.

\section{Discussion}

Giant prolactinomas, by consensus, are defined as prolactinomas which are greater than $4 \mathrm{~cm}$ in size, have a prolactin level of greater than $1,000 \mu \mathrm{g} / \mathrm{L}$ and do not co-secrete any other hormones [2-4]. The term "giant prolactinoma" was first coined by Symon in 1979 for prolactinomas measuring $>4 \mathrm{~cm}$ in size [5]. However evidence-based guidelines for the definition of a giant prolactinoma are lacking. Various criteria that have been considered in the past are local invasion, extending $2 \mathrm{~cm}$ above the jugulare sphenoidale, and a prolactin level of $>2,000 \mathrm{ng} /$ $\mathrm{mL}$ [6-8]. While giant prolactinomas can present with the classic features of a prolactinoma namely amenorrhea, galactorrhea, and visual field defects, they also can present in many ways given their large size, and high prolactin levels. The diagnosis may also be made difficult as giant prolactinomas occur earlier and also have a male preponderance as compared to conventional prolactinomas. 

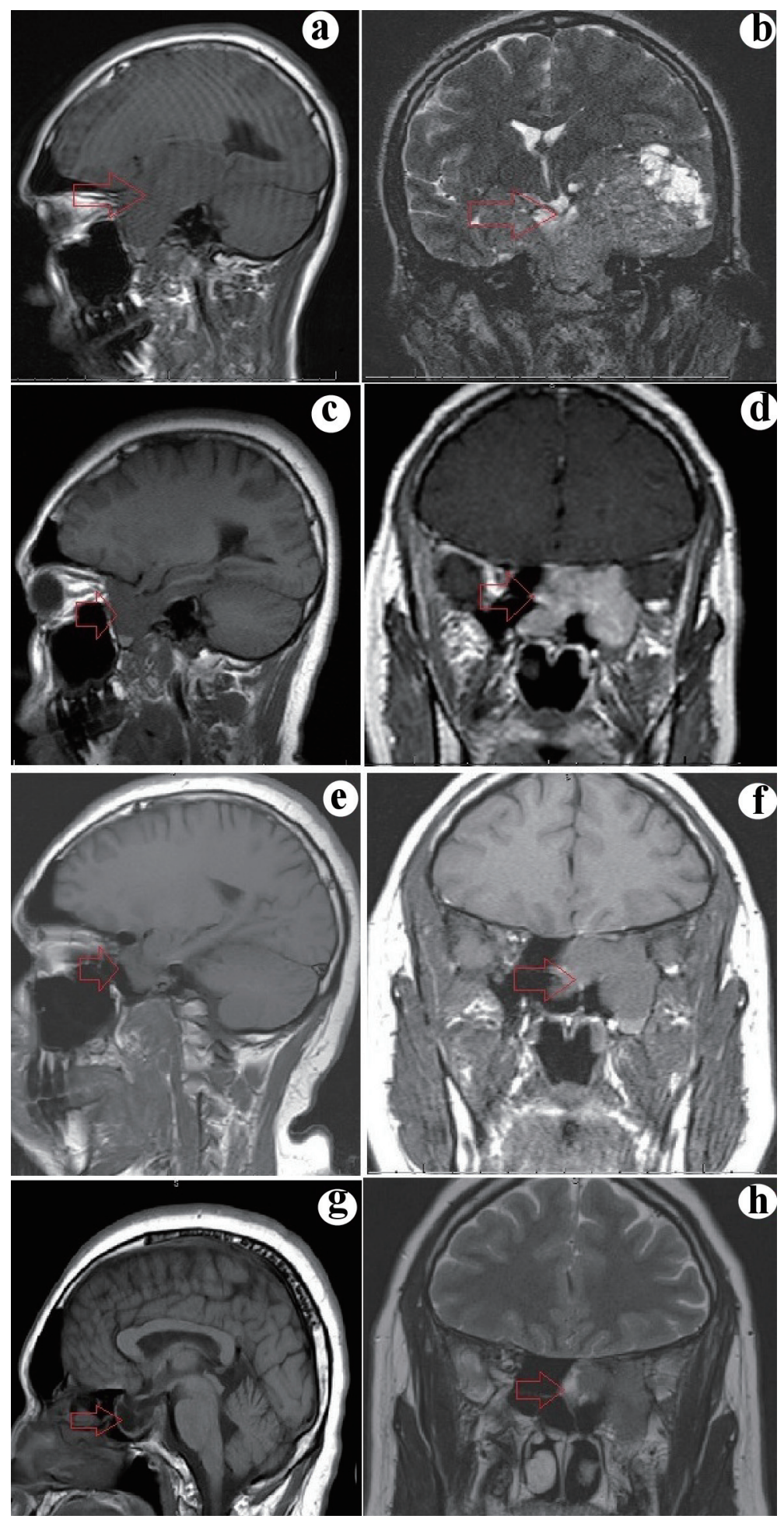

Figure 1. (a, b) Sagittal and coronal section of MRI showing a huge mass replacing the sphenoid sinus, extending laterally through the cavernous sinus and middle cranial fossa, compressing bilateral temporal lobe and left midbrain, superiorly involving the inferior third ventricle and ethmoid sinuses anteriorly. (c, d) Sagittal and coronal section of MRI 6 months after initiation of treatment show a significant reduction in the size of the tumor with clearance of the third ventricle and ethmoid sinus and persistent involvement of cavernous sinus and left temporal lobe. $(e, f)$ Sagittal and coronal section of MRI showing a further decrease in the size of the tumor $(3.2 \mathrm{~cm})$ and a reduction in the involvement of the left temporal lobe. $(\mathrm{g}, \mathrm{h})$ Sagittal and coronal section of MR showing a further decrease in the size of the tumor $(2.5 \mathrm{~cm})$ and a reduction in the involvement of the left temporal lobe. MRI: magnetic resonance imaging. 


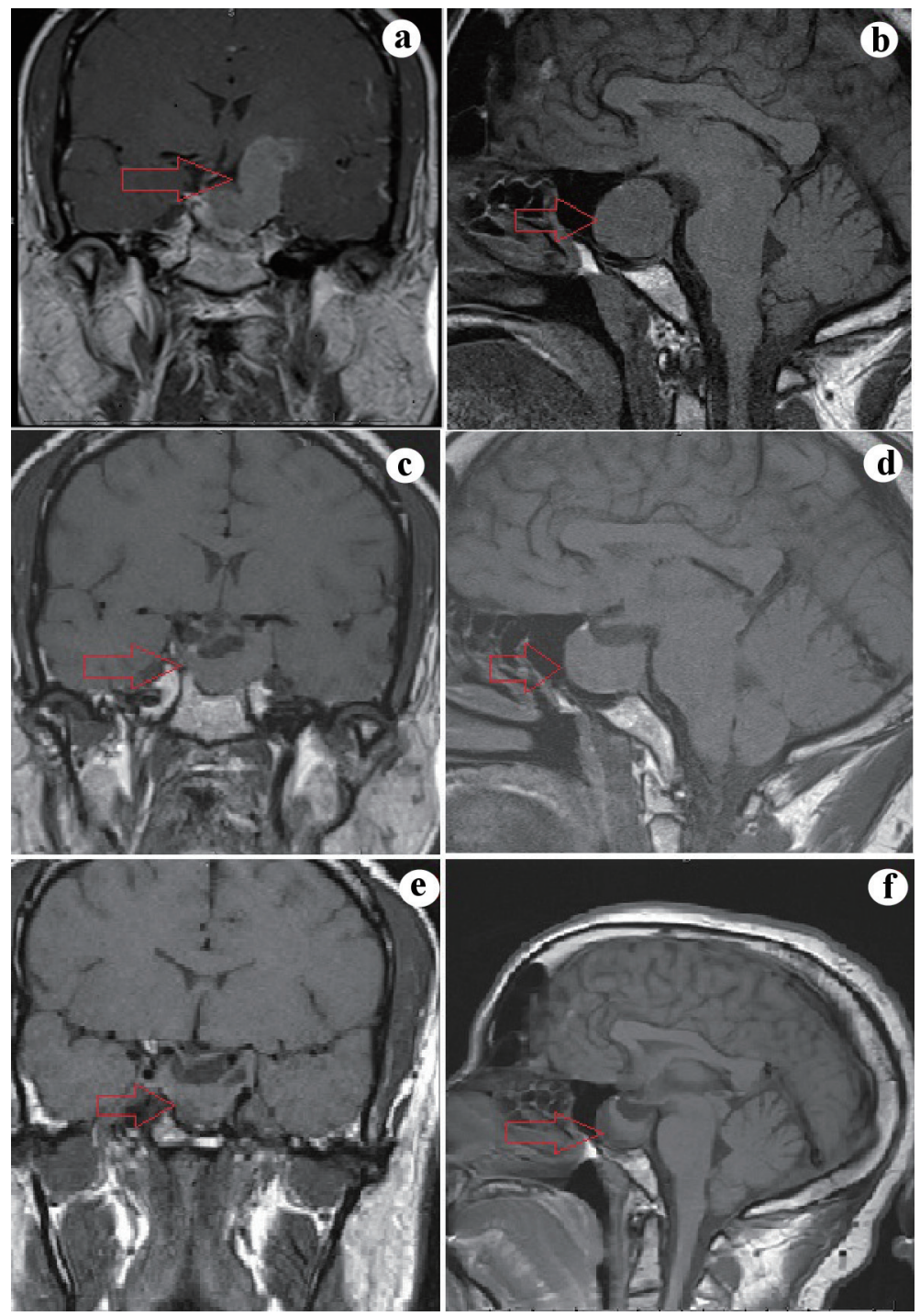

Figure 2. (a, b) Sagittal and coronal sections of the MRI showing a $4.3 \mathrm{~cm}$ sellar mass exerting mass effect on the optic chiasma and involving bilateral cavernous sinus and extending into the left temporal lobe. (c, d) Sagittal and coronal sections of the MRI 3 months later showing a decrease in the size of the sellar mass (2.7) and a decrease in the extent of temporal lobe involvement. $(e, f)$ Sagittal and coronal sections of the MRI after 6 years shows a persistent sellar mass $(2.5 \mathrm{~cm})$ with the continued involvement of the left cavernous sinus. MRI: magnetic resonance imaging.

About $75 \%$ women present with amenorrhea (primary and secondary) and $61 \%$ of men present with hypogonadism [9]. Hypopituitarism may be noted in $33 \%$ cases of giant prolactinomas. For example, the third patient in our case series presented with primary amenorrhea and short stature due to growth hormone deficiency.

Due to their large size and associated invasiveness, giant prolactinomas can involve various intracranial and extracranial structures (Fig. 5). Laterally, they can involve the cavernous sinus and result in cranial nerve palsies. Abducens nerve palsy can result in horizontal diplopia and is frequently the first manifestation. Involvement of the third and fourth cranial nerves can result in ptosis, vertical and diagonal diplopia [1013]. Rarely, ninth to 11th cranial nerve palsies can occur due to tumor extension into the inferior petrosal sinus [14]. Poste- rior growth of the tumor can involve the cerebellum and cause ataxia [9]. Anterior growth of the tumor can result in invasion of the nasopharynx or orbits causing nasal stuffiness and snoring or exophthalmos and optic nerve compression respectively [15-19]. Giant prolactinomas can also invade the foramen of Monro and result in hydrocephalus [20]. Frontal dementia can be secondary to invasion of the frontal lobe. Temporal lobe epilepsy characterized by automatisms, smacking, and olfactory hallucinations can be seen due to temporal lobe involvement as noted in our third patient [21,22].

CSF rhinorrhea can occur due to the rapid shrinkage of the tumor once treatment with dopamine agonists has been initiated. The rapid shrinkage causes tears in the dura resulting in CSF leaks. Rarely, spontaneous CSF rhinorrhea can also be observed [23]. Meningitis can occur if the CSF leak is not re- 


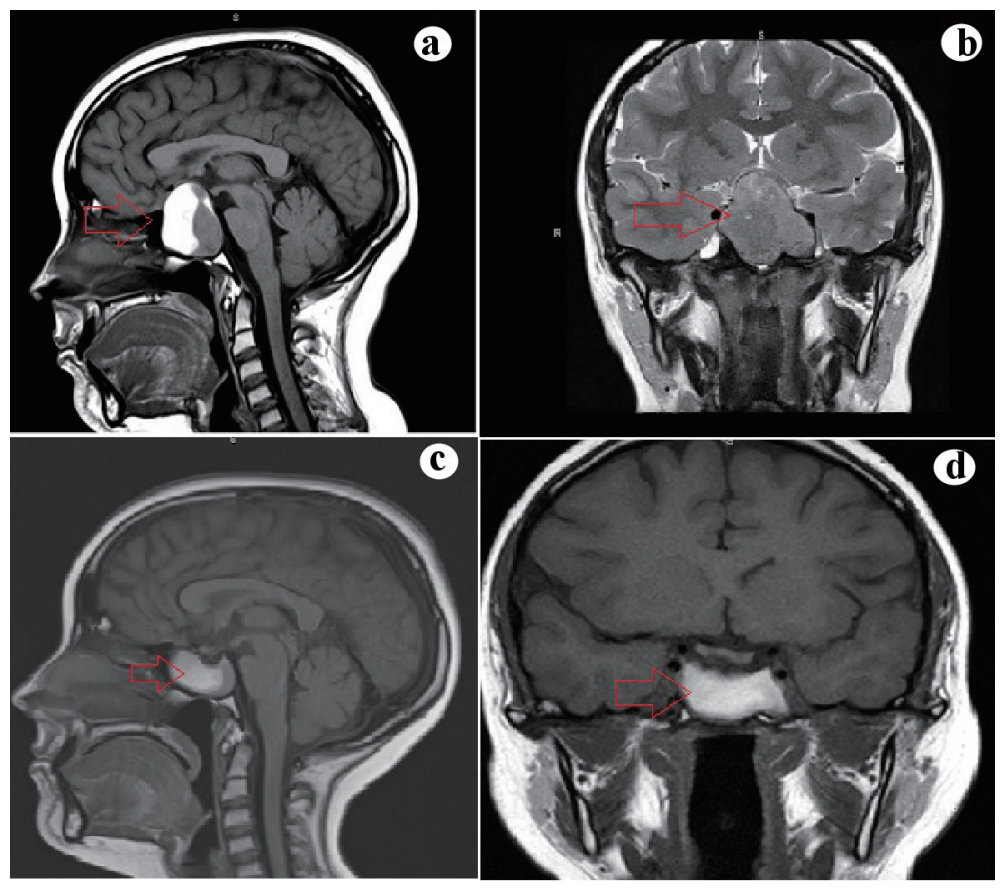

Figure 3. $(a, b)$ Sagittal and coronal sections of the MRI showing a $4 \mathrm{~cm}$ sellar mass involving the left cavernous sinus and exerting mass effect on the optic chiasma and prechiasmatic optic nerves. (c, d) Sagittal and coronal section of MRI 3 months later showing a decrease in the size of the mass $(3 \mathrm{~cm})$ without the involvement of the cavernous sinus and no mass effect on the optic chiasma. MRI: magnetic resonance imaging.

paired as observed in the first case [24].

Hormonal evaluation in giant prolactinomas reveals markedly elevated high levels of prolactin $(>1,000 \mu \mathrm{g} / \mathrm{L})$. However, occasionally such high levels may be reported as falsely low due to the "hook effect". Prolactin is measured by an enzyme-linked immunoassay (ELISA) assay which involves the binding of a prolactin molecule to a capture antibody and a detection antibody. These "capture antibody-prolactin-detection antibody" complexes are measured to get the prolactin levels. In cases with extremely high prolactin levels there is decreased formation of "capture antibody-prolactindetection antibody" complexes leading to a falsely low prolactin level being reported. Serial dilution (10 - 100 folds) of the sample will decrease the number of prolactin molecules in the sample, but will increase the formation of the "capture antibody-prolactin-detection antibody" complexes leading to an increase in prolactin level. This is known as the "hook effect" $[25,26]$.

CT or MRI can be used to assess the extent of involvement of the tumor. Giant prolactinomas can be mistaken for other brain tumors like meningioma, glioma or chordoma due to their size and atypical clinical presentations. Those which extend into the nasopharynx may be mistaken nasal polyps or nasopharyngeal carcinoma $[27,28]$. It is essential that every skull base tumor is assessed with a prolactin level as this may prevent unnecessary surgeries.

Dopamine agonists are the treatment of choice in giant prolactinomas. They are sensitive to dopamine agonists, and

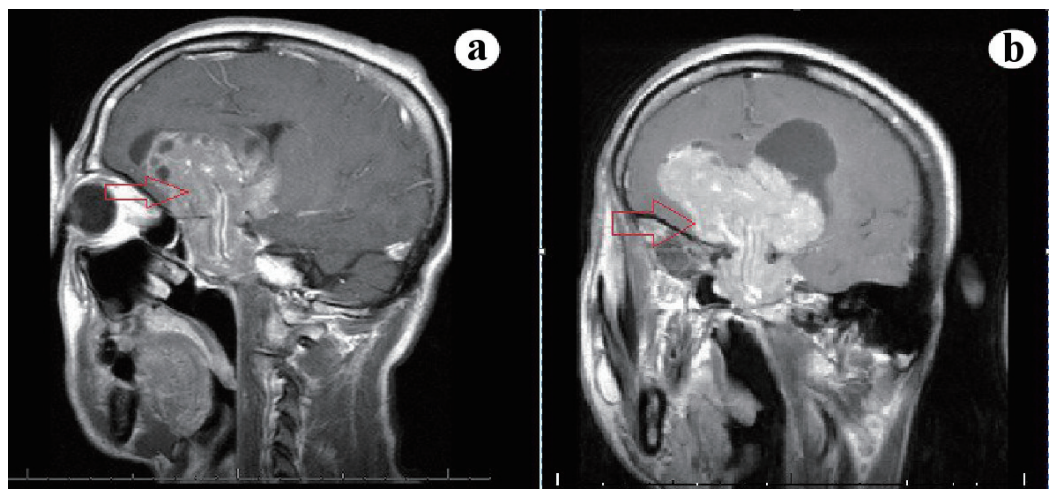

Figure 4. (a, b) Sagittal and coronal sections of MRI showing a giant sellar mass compressing the suprasellar structures and ventricular system. MRI: magnetic resonance imaging. 


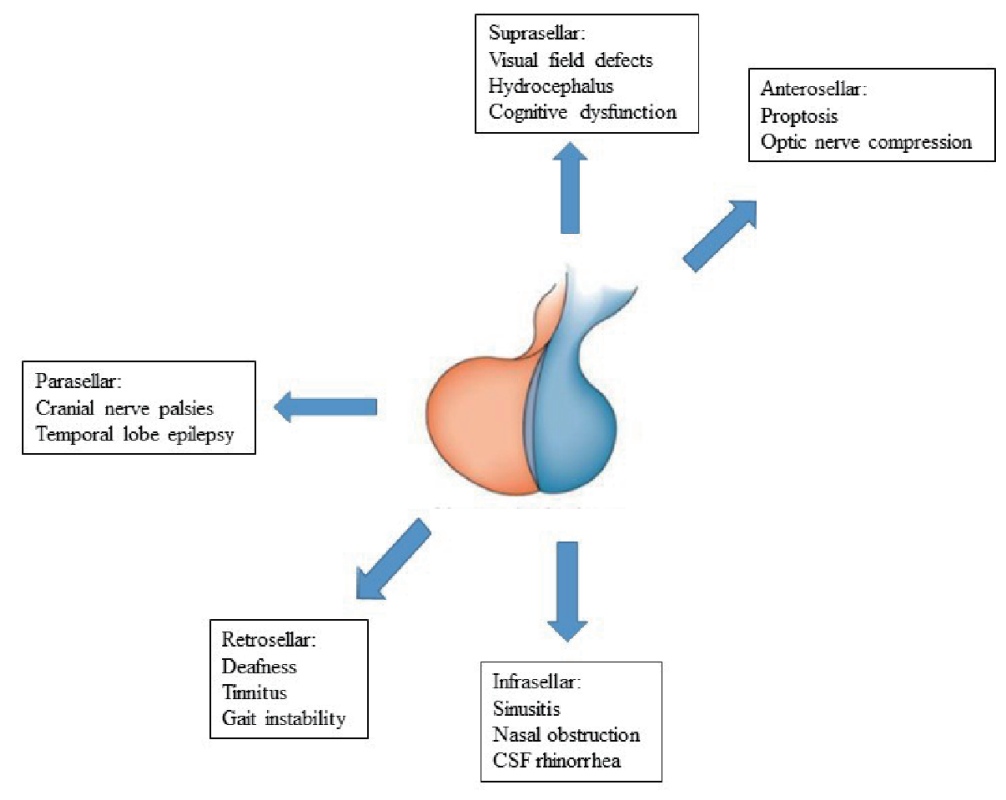

Figure 5. Symptoms and complications of giant prolactinomas. MRI: magnetic resonance imaging. CSF: cerebrospinal fluid.

treatment is started with conventional doses of either bromocriptine or cabergoline. There is a rapid resolution of neurological symptoms upon treatment with dopamine agonists. Improvement in visual fields can be seen in as early as 5 days even before there is a decrease in the size of the tumor $[8,29]$. Hydrocephalus secondary to giant prolactinomas may forego shunt procedures after a few days of treatment with dopamine agonists [19, 30, 31]. Resolution of proptosis on treatment with dopamine agonists has also been reported [17-19]. About $96 \%$ of patients experience visual improvement and $48 \%$ of patients have complete normalization of visual fields [9]. The decrease in size of the tumor is observed in about $74 \%$ cases, and this can be seen even in cases where the prolactin does not normalize. Careful monitoring for CSF leaks and pituitary apoplexy should be done once treatment with dopamine agonists has been started.

Surgery is indicated only in cases where the tumor is nonresponsive or progresses despite adequate medical treatment. However, even after surgery, residual tumor and hyperprolactinemia can persist and medical treatment may need to be continued [9]. Radiotherapy can be used in giant tumors which are progressive as an adjunct to medical treatment; however evidence regarding their efficacy is lacking [32]. Temozolomide is an alkylating agent used in the treatment of pituitary carcinomas which can be used in cases of resistant prolactinomas [33].

Somatostatin receptors (SST-1, 5 and rarely 2) are often expressed in prolactinomas making octreotide and pasireotide potential therapeutic options. Baldari et al demonstrated the efficacy of peptide receptor radionuclide therapy in a 58-year-old with cabergoline resistant prolactinoma in reducing the size of the tumor [13]. Fukuoka et al in rats and human prolactinoma cell lines have shown lapatinib, a tyrosine kinase inhibitor has a suppressive effect [34]. Future studies to identify novel molecular markers and therapeutic targets are needed to aid in the management of giant prolactinomas resistant to conventional treatment.

\section{Conclusions}

Giant prolactinomas are tumors which are greater than $4 \mathrm{~cm}$ in size and have a prolactin level of greater than $1,000 \mu \mathrm{g} / \mathrm{L}$. Unlike classical prolactinomas, they show a male preponderance (nine folds) and present 10 years earlier than conventional prolactinomas. They can present with atypical symptoms due to their big size and ability to invade surrounding structures. Therefore prolactin levels need to be checked in every skull base tumor. It should be borne in mind that a falsely low prolactin level can be due to the "hook effect", in such cases serial dilutions will reveal a paradoxical increase in the prolactin level.

Dopamine agonists are the treatment of choice and are often successful in normalizing prolactin and reducing the size of the tumor. However, careful monitoring for pituitary apoplexy and CSF leaks is necessary. Resistant prolactinomas may be treated with surgery, radiotherapy or temozolomide. The role of somatostatin receptor analog and peptide receptor radionucleotide therapy in prolactinoma management needs further research.

\section{Acknowledgments}

None to declare.

\section{Financial Disclosure}

None to declare. 


\section{Conflict of Interest}

None to declare.

\section{Informed Consent}

Written and informed consent has been obtained from the patients.

\section{Author Contributions}

GV, GS, PS, KS, KK were actively involved in writing the manuscript. GM was involved in expert review of imaging. LFL was the senior author involved in editing the manuscript.

\section{Data Availability}

The authors declare that data supporting the findings of this study are available within the article.

\section{References}

1. Delgrange E, Raverot G, Bex M, Burman P, Decoudier B, Devuyst F, Feldt-Rasmussen U, et al. Giant prolactinomas in women. Eur J Endocrinol. 2014;170(1):31-38.

2. Daly AF, Rixhon M, Adam C, Dempegioti A, Tichomirowa MA, Beckers A. High prevalence of pituitary adenomas: a cross-sectional study in the province of Liege, Belgium. J Clin Endocrinol Metab. 2006;91(12):4769-4775.

3. Fernandez A, Karavitaki N, Wass JA. Prevalence of pituitary adenomas: a community-based, cross-sectional study in Banbury (Oxfordshire, UK). Clin Endocrinol (Oxf). 2010;72(3):377-382.

4. Raappana A, Koivukangas J, Ebeling T, Pirila T. Incidence of pituitary adenomas in Northern Finland in 19922007. J Clin Endocrinol Metab. 2010;95(9):4268-4275.

5. Symon L, Jakubowski J, Kendall B. Surgical treatment of giant pituitary adenomas. J Neurol Neurosurg Psychiatry. 1979;42(11):973-982.

6. Grebe SK, Delahunt JW, Feek CM. Treatment of extensively invasive (giant) prolactinomas with bromocriptine. N Z Med J. 1992;105(931):129-131.

7. Cho EH, Lee SA, Chung JY, Koh EH, Cho YH, Kim JH, Kim CJ, et al. Efficacy and safety of cabergoline as first line treatment for invasive giant prolactinoma. J Korean Med Sci. 2009;24(5):874-878.

8. Shimon I, Benbassat C, Hadani M. Effectiveness of longterm cabergoline treatment for giant prolactinoma: study of 12 men. Eur J Endocrinol. 2007;156(2):225-231.

9. Maiter D, Delgrange E. Therapy of endocrine disease: the challenges in managing giant prolactinomas. Eur J Endocrinol. 2014;170(6):R213-227.

10. Schofl C, Schofl-Siegert B, Karstens JH, Bremer M, Lenarz T, Cuarezma JS, Samii M, et al. Falsely low serum prolactin in two cases of invasive macroprolactinoma. Pituitary. 2002;5(4):261-265.

11. Chattopadhyay A, Bhansali A, Masoodi SR. Long-term efficacy of bromocriptine in macroprolactinomas and giant prolactinomas in men. Pituitary. 2005;8(2):147-154.

12. Fleseriu M, Lee M, Pineyro MM, Skugor M, Reddy SK, Siraj ES, Hamrahian AH. Giant invasive pituitary prolactinoma with falsely low serum prolactin: the significance of 'hook effect'. J Neurooncol. 2006;79(1):41-43.

13. Baldari S, Ferrau F, Alafaci C, Herberg A, Granata F, Militano V, Salpietro FM, et al. First demonstration of the effectiveness of peptide receptor radionuclide therapy (PRRT) with $111 \mathrm{In}-\mathrm{DTPA}-\mathrm{octreotide}$ in a giant PRL-secreting pituitary adenoma resistant to conventional treatment. Pituitary. 2012;15(Suppl 1):S57-60.

14. Davis JR, Sheppard MC, Heath DA. Giant invasive prolactinoma: a case report and review of nine further cases. Q J Med. 1990;74(275):227-238.

15. Inagawa $H$, Ishizawa $K$, Mitsuhashi $T$, Shimizu $M$, Adachi J, Nishikawa R, Matsutani M, et al. Giant invasive pituitary adenoma extending into the sphenoid sinus and nasopharynx: report of a case with intraoperative cytologic diagnosis. Acta Cytol. 2005;49(4):452-456.

16. Care RH, Sunkaraneni VS, Theaker J, Harries PG. Rapidly progressing giant invasive prolactinoma. J Laryngol Otol. 2012;126(8):840-843.

17. Berwaerts J, Verhelst J, Abs R, Appel B, Mahler C. A giant prolactinoma presenting with unilateral exophthalmos: effect of cabergoline and review of the literature. J Endocrinol Invest. 2000;23(6):393-398.

18. Siddiqui A, Chew N, Miszkiel K. Case report: Unusual orbital invasion by a giant prolactinoma. Br J Radiol. 2008;81(971):e259-262.

19. Cackett P, Eunson G, Bath L, Mulvihill A. Proptosis as the presenting sign of giant prolactinoma in a prepubertal boy: successful resolution of hydrocephalus by use of medical therapy. Future Oncol. 2012;8(12):1621-1626.

20. Scarone P, Losa M, Mortini P, Giovanelli M. Obstructive hydrocephalus and intracranial hypertension caused by a giant macroprolactinoma. Prompt response to medical treatment. J Neurooncol. 2006;76(1):51-54.

21. Deepak D, Daousi C, Javadpour M, MacFarlane IA. Macroprolactinomas and epilepsy. Clin Endocrinol (Oxf). 2007;66(4):503-507.

22. Brisman MH, Fetell MR, Post KD. Reversible dementia due to macroprolactinoma. Case report. J Neurosurg. 1993;79(1):135-137.

23. Lam G, Mehta V, Zada G. Spontaneous and medically induced cerebrospinal fluid leakage in the setting of pituitary adenomas: review of the literature. Neurosurg Focus. 2012;32(6):E2.

24. Cappabianca P, Lodrini S, Felisati G, Peca C, Cozzi R, Di Sarno A, Cavallo LM, et al. Cabergoline-induced CSF rhinorrhea in patients with macroprolactinoma. Report of three cases. J Endocrinol Invest. 2001;24(3):183-187.

25. Comtois R, Robert F, Hardy J. Immunoradiometric assays may miss high prolactin levels. Ann Intern Med. 1993;119(2):173.

26. Haller BL, Fuller KA, Brown WS, Koenig JW, Eveland 
BJ, Scott MG. Two automated prolactin immunoassays evaluated with demonstration of a high-dose "hook effect" in one. Clin Chem. 1992;38(3):437-438.

27. Minniti G, Jaffrain-Rea ML, Santoro A, Esposito V, Ferrante L, Delfini R, Cantore G. Giant prolactinomas presenting as skull base tumors. Surg Neurol. 2002;57(2):99103; discussion 103-104.

28. Cook RJ, Uttley D, Wilkins PR, Archer DJ, Bell BA. Prolactinomas in men masquerading as invasive skull base tumours. Br J Neurosurg. 1994;8(1):51-55.

29. Saeki N, Nakamura M, Sunami K, Yamaura A. Surgical indication after bromocriptine therapy on giant prolactinomas: effects and limitations of the medical treatment. Endocr J. 1998;45(4):529-537.

30. Iglesias P, Macho LP, Diez JJ. Resolution of macroprolactinoma-induced symptomatic hydrocephalus following cabergoline therapy. Age Ageing. 2004;33(4):410-412.

31. Zikel OM, Atkinson JL, Hurley DL. Prolactinoma manifesting with symptomatic hydrocephalus. Mayo Clin Proc. 1999;74(5):475-477.

32. Yang MY, Shen CC, Ho WL. Treatments of multi-invasive giant prolactinoma. J Clin Neurosci. 2004;11(1):7075.

33. Raverot G, Castinetti F, Jouanneau E, Morange I, Figarella-Branger D, Dufour H, Trouillas J, et al. Pituitary carcinomas and aggressive pituitary tumours: merits and pitfalls of temozolomide treatment. Clin Endocrinol (Oxf). 2012;76(6):769-775.

34. Fukuoka H, Cooper O, Mizutani J, Tong Y, Ren SG, Bannykh S, Melmed S. HER2/ErbB2 receptor signaling in rat and human prolactinoma cells: strategy for targeted prolactinoma therapy. Mol Endocrinol. 2011;25(1):92-103. 